\title{
A INFLUÊNCIA DO PODER LEGISLATIVO NO PLANEJAMENTO DAS POLÍTICAS PÚBLICAS DE EDUCAÇÃO NO ESTADO DE MINAS GERAIS ${ }^{1}$
}

\author{
André Dell'Isola DENARDI ${ }^{2}$ \\ Bruno Lazzarotti Diniz COSTA ${ }^{3}$
}

\begin{abstract}
Resumo
O trabalho analisa o papel da Assembleia Legislativa de Minas Gerais na elaboração e nas discussões do mais recente Plano Estadual de Educação. Baseado nas arenas de debate disponíveis para a discussão do Plano, na identificação dos grupos sociais envolvidos e na mobilização em torno de seus diferentes temas, busca-se avaliar o grau de influência da Assembleia de Minas nesta política específica. A partir de um modelo analítico institucionalista e pluralista, amparado pela análise de documentação disponibilizada pelos órgãos diretamente envolvidos com o Plano, argumenta-se que a natureza das arenas e das regras decisórias conformaram as alterações e o perfil final do Plano. Baseado nos resultados obtidos, conclui-se sobre a importância do Poder Legislativo como vetor de promoção do debate público em torno do Plano, através de plataformas variadas de participação popular.
\end{abstract}

Palavras-chave: Parlamento. Políticas Públicas. Planejamento do Ensino. Democracia. Participação Popular.

\footnotetext{
${ }^{1} \mathrm{O}$ presente trabalho é resultado de dissertação no programa de Pós-Graduação da Fundação João Pinheiro, cuja versão preliminar foi apresentada no III ENEPCP - Encontro Nacional de Ensino e Pesquisa do Campo de Públicas.

2 Mestre em Administração Pública pela Fundação João Pinheiro, Especialista em Poder Legislativo e Políticas Públicas pela Escola do Legislativo da Assembleia de Minas, Bacharel em Direito (PUC) e em Ciências do Estado (UFMG).

E-mail: andredenardi90@gmail.com

${ }^{3}$ Pesquisador efetivo da Fundação João Pinheiro, Doutor em Sociologia e Política (UFMG), Mestre em Sociologia (UFMG), graduado em Ciências Sociais (UFMG).

E-mail: bruno.diniz@fjp.mg.gov.br
} 
THE INFLUENCE OF THE LEGISLATIVE POWER IN THE PLANNING OF PUBLIC EDUCATION POLICY IN THE STATE OF MINAS GERAIS

\author{
André Dell'Isola DENARDI
}

Bruno Lazzarotti Diniz COSTA

\begin{abstract}
This paper analyzes the role of the Minas Gerais Legislative Assembly in the elaboration and discussion of the most recent State Education Plan. Based on the available debate arenas for the discussion of the Plan, on the identification of the social groups involved and on the mobilization around its different themes, we seek to evaluate the Assembly's degree of influence over this specific policy. Through an institutionalist and pluralistic analytical framework, supported by the analysis of documentation provided by the organizations directly involved with the Plan, it is argued that the nature of the arenas and decision guidelines shaped the changes and final profile of the Plan. Based on the obtained results, a conclusion is reached about the importance of the Legislative Power as a vector of promotion for the public debate around the Plan, through varied platforms of popular participation.
\end{abstract}

Keywords: Parliament. Public Policy. Educational Planning. Democracy. Popular Participation. 


\title{
LA INFLUENCIA DEL PODER LEGISLATIVO EN LA PLANIFICACIÓN DE LAS POLÍTICAS DE EDUCACIÓN PÚBLICA EN EL ESTADO DE MINAS GERAIS
}

\author{
André Dell'Isola DENARDI
}

Bruno Lazzarotti Diniz COSTA

\section{Resumen}

El documento analiza el papel de la Asamblea Legislativa de Minas Gerais (ALMG) en la elaboración y discusión del más reciente Plan de Educación del Estado (PEE). Con base en los foros de debate disponibles para la discusión del Plan, la identificación de los grupos sociales involucrados y la movilización en torno a sus diferentes temas, buscamos evaluar el grado de influencia de la Asamblea de Minas en esta política específica. Desde un modelo analítico institucionalista y pluralista, respaldado por el análisis de la documentación proporcionada por los organismos directamente involucrados en el Plan, se argumenta que la naturaleza de las arenas y las reglas de decisión moldearon los cambios y el perfil final del Plan. Con base en los resultados obtenidos, se concluye sobre la importancia del Poder Legislativo como vector de promoción del debate público en torno al Plan, a través de diversas plataformas de participación popular.

Palabras clave: Parlamento. Políticas Públicas. Planeamiento del Enseño. Democracia. Participación Popular. 


\title{
Introdução
}

Os trabalhos sobre o processo de formulação de políticas públicas no Brasil têm enfatizado o protagonismo do Executivo, tanto no desenho e formulação quanto na iniciativa, dominância e coordenação de sua face legislativa, quando é o caso. Não sem razão, como enfatizam as avaliações sobre o presidencialismo de coalizão, arranjo político de governo e recrutamento de apoio legislativo em países que combinam presidencialismo com multipartidarismo, ou seja, em que a maioria governativa é construída antes, durante e após o processo eleitoral e envolve coalizões partidárias, muitas vezes amplas e heterogêneas. A maior parte dos trabalhos aponta quais estratégias, recursos políticos e mecanismos institucionais permitem que o Executivo coordene e mantenha a coalizão e assegure iniciativa, sucesso e dominância legislativa. Da mesma maneira, os trabalhos sobre inovações democráticas e instituições participativas destacam o papel do Executivo na constituição, convocação, estabelecimento de agenda e mobilização da sociedade civil para a participação em espaços de deliberação, como os conselhos e conferências. Diante desse contexto, a dinâmica de implementação de políticas é analisada por Couto (2019, p. 105) da seguinte forma:

\begin{abstract}
Uma mesma política requer, para sua implementação, a utilização articulada de diversos mecanismos decisórios, de modo que não se pode chegar a conclusões de caráter geral acerca do funcionamento do sistema político-institucional sem que se leve em conta tal articulação. Os mecanismos que podem ser acionados variam em função das medidas específicas que se pretende implementar, dos desafios ambientais postos pela conjuntura particular que se vive e da gama de apoios que os propugnadores das políticas conseguem amealhar dentro e fora das instâncias decisórias institucionais.
\end{abstract}

O presente trabalho analisa um caso distinto, em que, em primeiro lugar, o Legislativo assume o papel de coordenador entre Executivo, legisladores e cidadãos e movimentos sociais no debate sobre o Plano Estadual de Educação (PEE). Em segundo lugar, como se verá adiante, diferentes arenas de deliberação são constituídas nesse processo. O trabalho mostra como as características institucionais de cada arena deslocam a participação, o protagonismo, o poder de agenda e a capacidade de incidir sobre os resultados entre diferentes atores e interesses. Do ponto de vista mais analítico, discute-se como distintos loci institucionalizados distribuem desigualmente custos e poder, valorizando determinados recursos políticos em detrimento de outros, incidindo sobre a eficácia percebida das estratégias dos distintos atores, o que faz com que, a partir da avaliação de seus interesses e recursos políticos, eles priorizem algumas arenas, e não outras. Deste ponto de vista, espera-se contribuir para o debate sobre o papel do Legislativo como formulador de políticas e como instituição que, sob certas condições, é capaz de coordenar as relações entre governo, representantes e cidadãos e movimentos sociais, mesmo no nosso modelo de presidencialismo, no qual o protagonismo é, via de regra, do Executivo. Este artigo é também uma contribuição para os estudos das 
instituições participativas e interfaces socioestatais, geralmente centrados em iniciativas do Poder Executivo.

No Brasil pós-redemocratização, as atribuições do Estado para a garantia de uma educação de qualidade e universal possuem sua principal previsão no texto constitucional. Estabelecida pela Constituição Federal como direito social, a educação é tida como dever do Estado e da família, promovida e incentivada com a colaboração da sociedade, sendo sua competência comum entre União, estados, Distrito Federal e municípios, conforme Artigos 6º 24, IX, 30, VI e 205 da Constituição Federal. Trata-se, portanto, de um dos mais importantes direitos sociais, sem o qual é impossível se chegar aos demais. Especificamente no caso de Minas Gerais, a Constituição Estadual - em seus Artigos 2º VII, 196 e incisos, 198 e incisos - elenca a garantia da educação como uma das prioridades do estado. Assim, compete ao estado-membro a difusão da educação, cuja base é o ensino nos princípios da igualdade, liberdade, pluralidade, gratuidade, meritocracia, qualidade e democracia, atuando prioritariamente no ensino médio e complementarmente nas demais etapas, em parceria com a União e os municípios. O alinhamento do Brasil e, por consequência, do estado de Minas Gerais com as propostas levantadas nas Conferências Mundiais de Educação para Todos trouxe impactos diretos sobre a forma como as políticas voltadas à educação devem ser pensadas, elaboradas, consultadas, executadas, conduzidas e fiscalizadas pelo Poder Público, sempre permeadas de ampla participação popular. Com relação à experiência na promoção da participação e deliberação popular:

Entre os Legislativos estaduais brasileiros, a Assembleia Legislativa de Minas Gerais (ALMG) é apontada como uma das que têm experimentado práticas mais ricas no que concerne à gestão da informação e ao fomento de interlocução com a sociedade. Ainda que esse processo se ligue profundas mudanças por que passou o Brasil após a redemocratização, o contexto nacional mais amplo não explica todo o processo da ALMG, o que se faz evidente por sua singularidade entre assembleias estaduais (CUNHA; MENDONÇA, 2016, p. 282).

Como previsão constitucional, os Planos de Educação traçam metas e estratégias nos diversos aspectos do sistema de ensino para um prazo de dez anos e podem ser de nível nacional, estadual ou municipal. No esteio da consolidação do diálogo entre Estado e sociedade em geral desde a redemocratização, os Plano são acompanhados por amplos debates públicos, visando aproximar seu conteúdo de preferências e anseios da população, em especial a mais diretamente envolvida com o sistema de ensino. Como instituição que busca ser a estratificação social da população como um todo, o Poder Legislativo exerce relevante papel na condução desses debates, desenvolvendo plataformas de discussão que reúnem diferentes atores e agendas vindas da sociedade. Ao mesmo tempo que o formato dessas plataformas de discussão influencia no tipo de resultado final para o conteúdo do Plano de Educação, essas mesmas plataformas são influenciadas pelo próprio desenho institucional do Legislativo, sua composição partidária e suas disputas por interesses distintos. 
Para melhor identificar a atuação dos diferentes grupos envolvidos na elaboração do Plano e, ao mesmo tempo, analisar a atuação do Legislativo em todo o processo de tramitação do Plano no seu âmbito, foram especificadas cinco diferentes arenas de discussão, cada qual com suas respectivas peculiaridades, regras e objetivos. São elas: o Fórum Técnico (no qual se separou as etapas regionais da final) e a Tramitação Legislativa. Baseado no contorno de cada uma dessas arenas e em seus principais objetivos, foi possível observar como diferentes atores recorreram a diferentes estratégias em cada uma dessas etapas para fazer valer seus interesses. Por meio dos setores internos responsáveis pela condução dos trabalhos envolvendo o PEE no legislativo mineiro, pode-se aferir a qualidade de sua tramitação, tanto do ponto de vista técnico quanto do político. A composição parlamentar das comissões de mérito, a condução dos debates em torno do Plano nos Fóruns Técnicos Regionais e a garantia da devida tramitação pelas Gerências da Diretoria de Processo Legislativo, a cobertura dos trabalhos pelas Gerências da Diretoria de Comunicação Institucional: todas essas questões têm um impacto no resultado final do Plano no âmbito da ALMG.

Baseado nas arenas de discussão elencadas pelo estudo, na disposição de atores e no uso de estratégias específicas em cada uma delas e, principalmente, na forma como a estrutura técnica e política da Assembleia Legislativa se movimentou para dar suporte e contorno ao conteúdo do Plano, é possível estabelecer se o papel do Legislativo mineiro no processo de construção do PEE foi bem exercido. Isto posto, os objetivos específicos deste trabalho consistiram em: resgatar o desenho institucional das políticas de educação no Brasil para melhor compreender a trajetória do sistema de ensino em Minas Gerais; avaliar a trajetória de nosso modelo federativo com foco nas competências e nos recursos do estado-membro; analisar os principais mecanismos de atuação da ALMG que permitem impactar nas políticas públicas do estado; analisar quantitativa e qualitativamente de que maneira o Poder Legislativo mineiro atuou na elaboração do mais recente PEE. Considerando as atribuições constitucionais do Poder Legislativo e sua atuação pregressa na criação de espaços de discussão sobre políticas públicas diversas, trabalhou-se com a expectativa de que a Assembleia de Minas trataria o Plano de forma profunda, buscando articular atores e grupos diretamente envolvidos no tema, bem como a população como um todo, em torno de seu conteúdo.

\section{Metodologia}

A metodologia desta investigação se vale principalmente da técnica de coleta e análise de dados, compreendendo cinco etapas, cada uma relacionada a uma das arenas de discussão do PEE no âmbito da ALMG. A primeira consistiu no levantamento de dados a respeito das etapas de Interiorização e Final do Fórum Técnico, realizado nos meses de fevereiro a junho de 2016. Em ambas as etapas, foram usados os Documentos Finais de cada um dos 12 Encontros Regionais e da Etapa Final, especificando quais 
foram as intervenções no conteúdo do Plano em cada evento. De igual forma, as sugestões trazidas pela Consulta Pública via Internet estão disponibilizadas por meio de documentos consolidados.

A etapa seguinte se refere à Tramitação Legislativa, que foi analisada por meio do Sistema de Tramitação Legislativa (STL), que disponibiliza todos os pareceres das Comissões pelas quais passou o Plano, bem como as emendas apresentadas em Plenário.

Outras informações que contribuíram para o acompanhamento mais detalhado do Plano na ALMG foram disponibilizadas pela Gerência de Imprensa e Comunicação da Assembleia e por meio de relatórios gerados pela Gerência de Projetos Institucionais (GPI) e Escola do Legislativo.

Para além desse procedimento de coleta de dados, foram realizadas entrevistas com participantes e principais envolvidos na construção e no acompanhamento dos planos (Consultoria Legislativa de Educação, GPI e parlamentares envolvidos mais diretamente na discussão do Plano).

\section{O Papel do Legislativo nas Políticas Públicas}

Como promotor amplo e plural das demandas populares, o parlamento exerce um importante papel no aperfeiçoamento e debate em torno das políticas públicas. Por meio de seus representantes eleitos e sua estrutura técnica especializada, é capaz de envolver os mais diversos atores sociais e políticos em torno de planos, programas e ações de iniciativa do Estado, resultando em políticas públicas mais sofisticadas e endossadas pela população em geral. Os resultados (outputs) políticos do parlamento estão relacionados às iniciativas de modificação dentro do processo legislativo (emendas ou substitutivos apresentados em comissões ou plenário), resultados de eventos institucionais que dialogam com o cidadão, estratégias de obstrução do bloco minoritário, impactos da mídia tradicional e a incorporação de novas tecnologias na comunicação com a sociedade em geral (ANASTASIA; SANTOS, 2016). O modelo interativo de formulação de políticas públicas de Thomas e Grindle (1990) serve como importante modelo de análise para avaliar de que forma e em quais momentos o Legislativo pode influenciar nesse processo.

Com base nesse modelo interativo, constata-se que a Assembleia de Minas concentrou sua atuação no quesito "Arenas”, que envolve, num ponto, as características da política e, no outro, os segmentos burocrático e público. Dessa forma, a promoção dos debates em torno do Plano em todas as decisões deram forma às características das políticas públicas contidas no projeto aprovado do PEE. Por meio do chamamento público para participação do Fórum Técnico, da mobilização das forças políticas internas do parlamento, do Executivo Estadual, de algumas forças de nível municipal e da sociedade civil em geral, foi possível constatar como a capacidade de organização de cada grupo envolvido, bem como a orientação ideológica de stakeholders mais 
importantes no processo decisório, influenciou no contorno final do Plano. Dessa forma, o resultado da deliberação parlamentar a respeito dos projetos que passam pela tramitação legislativa envolve um número de atores, arenas e interesses cada vez mais crescente e plural.

Figura 1 - Modelo interativo de formulação de políticas públicas

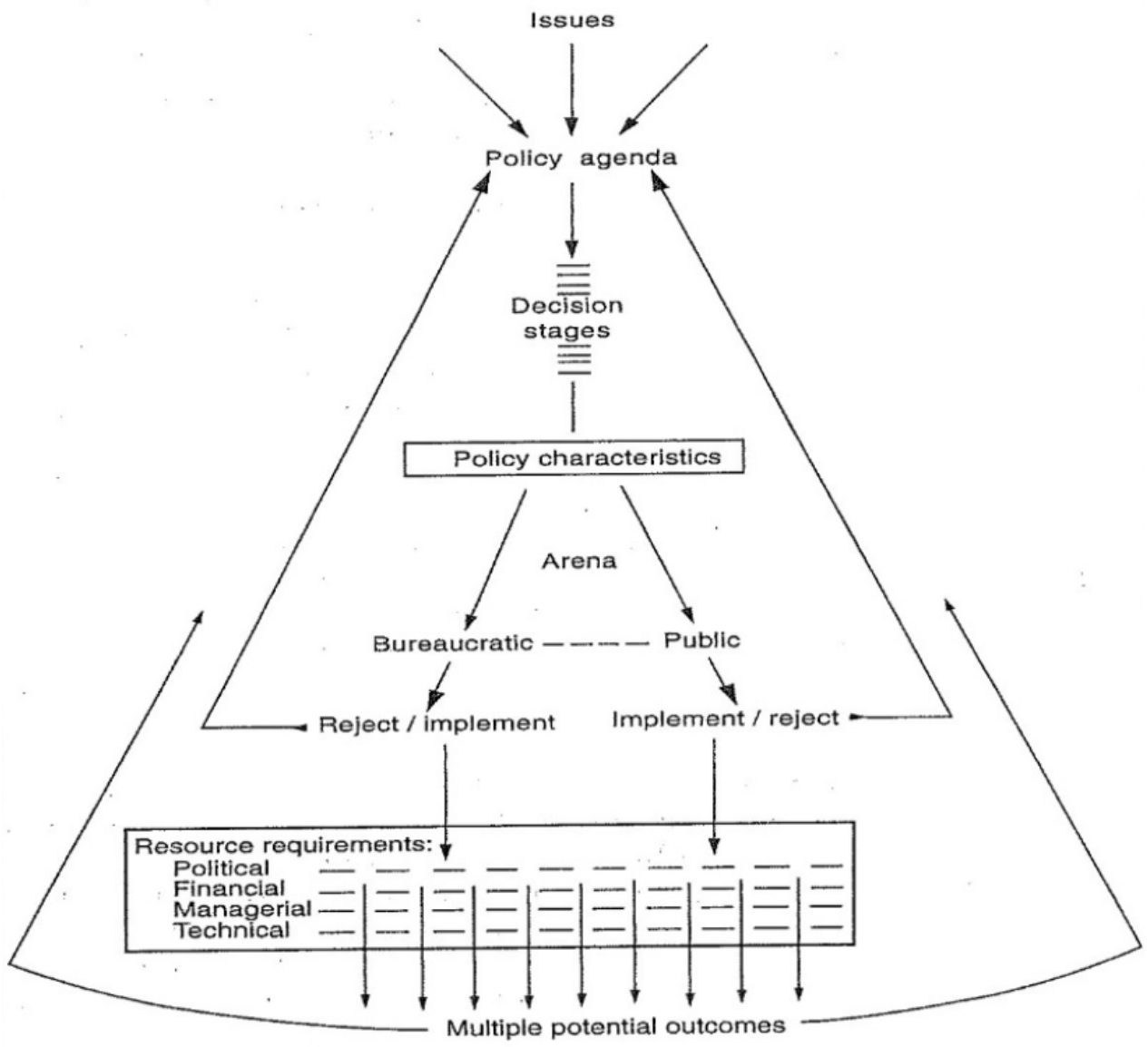

Fonte: THOMAS; GRINDLE, 1990.

A depender das regras postas em cada arena, determinados atores são beneficiados e, baseado nessa disposição de forças, organizam suas estratégias, seja por movimentos visando arenas outras que serão mais vantajosas, seja usufruindo da vantagem que já possuem em alguma. Nas palavras de Mandelkern:

Estratégias de planejamento legislativo focadas nos resultados da produção legal têm sido adotadas, com considerável impacto no processo legislativo e nas interações entre o Parlamento e os demais atores políticos e institucionais. Nessa direção, a legística ganhou centralidade nas agendas de mudanças no ambiente legislativo, com a redefinição de novos princípios e parâmetros para a avaliação da utilidade, da eficácia e da efetividade dos atos normativos. Nessa linha, argumenta-se que a qualidade da legislação é afetada positivamente quando são considerados os seguintes princípios: a. Da necessidade efetiva de novas decisões legislativas e atos normativos; b. Da proporcionalidade entre vantagens e custos associados à adoção 
de determinadas decisões legislativas; c. Da subsidiariedade, ou do incentivo para que as decisões sejam tomadas no nível mais próximo do cidadão; d. Da transparência, mediante o uso sistemático de consulta pública nos processos decisórios; e. Da responsabilidade, relativa à identificação dos agentes implicados; f. Da inteligibilidade (coerência e acessibilidade); e g. Da simplicidade da legislação (codificação e consolidação das leis) (MANDELKERN, 2001, p. 80, tradução nossa).

Com a queda de regimes ditatoriais nos anos 80 e 90, tanto o Brasil quanto Minas Gerais dão mais musculatura aos seus respectivos legislativos, por meio de atribuições constitucionais que lhes conferem poder fiscalizatório de fato sobre os atos do Poder Executivo, poder normativo e de promoção da participação popular no processo decisório de ações e políticas públicas. Com parlamentos mais fortes, o processo de elaboração das políticas públicas passa a ser mais construtivo, com outputs mais sustentáveis, baseados num maior consenso social e mais lastreado em aspectos técnicos (SAIEGH, 2010). Tal conjuntura representa uma nova postura do cidadão comum perante as decisões do Estado, tendo em vista que a sociedade civil passa agora a ser um ator de relevância no processo de construção de políticas públicas.

\section{A Tramitação do Plano Estadual de Educação na Assembleia de Minas}

Tanto o Plano Nacional de Educação (PNE) quanto o PEE buscam superar incoerências e limitações do sistema público de ensino que refletem, muitas vezes, os contrastes socioeconômicos sedimentados no país há gerações. Ao mesmo tempo, buscam esses objetivos por meio de uma construção coletiva de políticas públicas, permeada pela participação popular e conduzida da maneira mais harmônica possível entre os Poderes constituídos. Por tudo que foi dito a respeito do papel do Poder Legislativo na atualidade, a expectativa é que a ALMG tenha cumprido com suas atribuições constitucionais, promovendo o debate público em torno do Plano Estadual e contribuindo efetivamente para a sofisticação de seu conteúdo.

O projeto original do PEE - entregue à ALMG pelo Executivo Estadual, em setembro de 2015 - seguia basicamente o mesmo contorno do que havia sido proposto no PNE. Vinte metas dispostas no mesmo formato e com os objetivos: universalização do ensino infantil (meta 1), fundamental (meta 2), médio (meta 3), inclusão para população deficiente (meta 4), universalização da alfabetização para crianças (meta 5), ampliação da educação em tempo integral (meta 6), qualidade da educação básica de acordo com melhoria do Ideb (meta 7), elevação da escolaridade média (meta 8), da taxa de alfabetização da população com 15 anos ou mais (meta 9), integração da Educação de Jovens e Adultos (EJA) à educação profissional (meta 10), expansão das matrículas do ensino técnico (meta 11), elevação da taxa de matrículas no ensino superior (meta 12), ampliação do número de mestres e doutores no corpo docente (meta 13), da oferta de matrículas nestas mesmas modalidades de pós-graduação (meta 14), do número de 
professores do ensino básico com ensino superior (meta 15) e pós-graduação (meta 16), valorização do magistério (meta 17), revisão dos planos de carreira docentes (meta 18), gestão democrática da educação (meta 19) e ampliação do investimento público em educação (meta 20).

A influência da Assembleia de Minas exercida sobre o projeto original do Plano pode ser percebida em todos os elementos básicos presentes na formação de uma política pública (MOLINA, 2002). Pela natureza de seu conteúdo, tramitou pelas Comissões de Administração Pública, Constituição e Justiça, Fiscalização Financeira e Orçamentária e Educação, Ciência e Tecnologia, sendo esta última a responsável pela promoção dos Fóruns Técnicos Regionais, que levaram a discussão do Plano pelo estado.

Por meio da participação popular e das deliberações entre os parlamentares, que permearam toda a tramitação legislativa do Plano, houve uma série de alterações nas definições de problemas, geração e seleção de opções e gestão da opção selecionada, além do futuro monitoramento de sua execução e avaliação dos resultados pretendidos. Por suas diretrizes de médio prazo, capazes de influenciar direta ou indiretamente toda a população do estado, envolveu a disputa de uma multiplicidade de grupos sociais e políticos pelo melhor enquadramento de cada uma das metas e estratégias contidas no Plano. Tal fato é visto de forma positiva para a consolidação do processo de formação de políticas públicas contemporâneo, tendo em vista que:

\begin{abstract}
A importância de cada uma das atividades do modelo está relacionada em grande parte, pela forma como ocorre a participação de diversos interessados. Quanto mais participativa, maior a possibilidade de enriquecimento com diferentes visões, a definição do problema e a geração de opções. A participação proporciona maior solidez, relevância e sustentabilidade à ação. Além disso, com maior participação, os resultados esperados podem ser especificados de maneira muito melhor, além de permitir que os envolvidos se sintam mais comprometidos e ansiosos para melhorar os resultados alcançados (MOLINA, 2002, p. 8).
\end{abstract}

Esta interação dinâmica e pluridirecional entre diferentes setores da sociedade sobre o plano foi catalisada pelas arenas de discussão conduzidas pela ALMG, suas comissões permanentes (em especial a de Educação Ciência e Tecnologia) e gerências técnicas de apoio. Através do intercâmbio de informações realizado entre especialistas da área de educação, profissionais de ensino e interessados no tema, foram elaboradas e votadas centenas de sugestões de alteração do projeto em todas as suas metas. O processo de empoderamento dos usuários da política por meio da tomada de decisão democrática, no entanto, não significa necessariamente uma condução harmônica das deliberações. Não apenas em função dos conflitos de interesse dos grupos sociais e políticos envolvidos, mas pela própria condução do projeto, que experimentou a troca da composição das comissões de mérito em plena tramitação.

Tanto a estrutura desenvolvida especialmente para construir e discutir o PEE (Comissão Organizadora, Fórum Técnico) quanto a estrutura permanente de debate da Assembleia Legislativa (Comissões, Audiências Públicas, Plenário) permitiram a 
mobilização de diferentes atores em torno de diferentes temas, valendo-se de diferentes recursos para alcançar seus objetivos. O formato de cada arena favoreceu determinadas entidades em detrimento de outras. Baseado no formato final em que o Plano foi aprovado, pode-se afirmar que as entidades que melhor se organizaram em torno do convencimento dos parlamentares obtiveram os maiores ganhos. Isso não significou, no entanto, que a grande mobilização em torno dos Encontros Regionais e Etapa Final do Fórum Técnico não tenha gerado importantes resultados, como se verá adiante.

\section{O Fórum Técnico do Plano Estadual de Educação}

A interiorização das discussões do PEE por meio dos Encontros Regionais foi uma das arenas de debate mais profundas e elaboradas no processo de tramitação do Plano na Assembleia Legislativa. Foi a oportunidade de colocar seu conteúdo o mais próximo possível das diferentes realidades do estado, resultando numa coletânea de propostas de alterações bastante diversificada, pensadas e debatidas por uma pulverizada rede de atores políticos e sociais ao redor de Minas. De acordo com Sebastian (1999, p. 39, tradução nossa):

Todos os agentes que participam de alguma forma na concepção, aprovação, implementação e avaliação de uma política, seja funcionários do governo, políticos, técnicos, fornecedores, operadores ou construtores, beneficiários, são seres humanos com interesses diversos que podem ser afetados pela execução de uma política. Esses interesses podem diferir, como sempre acontece, e a política pode falhar se o conflito de interesses não for resolvido. É por isso que é essencial, quando se está desenhando uma mudança, realizar uma análise das partes envolvidas, para prevenir e solucionar conflitos de interesse antes que eles ocorram.

Como tratado anteriormente, o projeto PEE de Minas Gerais, elaborado pelo governo estadual na forma no Projeto de Lei $n^{\circ}$ 2.882/2015, foi composto originalmente por 15 artigos e um anexo contendo 20 metas específicas. Com o fim de facilitar as discussões ao longo do Fórum, o Regulamento organizou as metas em oito grupos temáticos, conforme a natureza de seus conteúdos.

Quadro 1 - Disposição das metas do PEE organizadas por grupos temáticos para o Fórum Técnico

\begin{tabular}{|c|c|}
\hline Grupos & Metas \\
\hline Grupo 1 - Acesso e universalização & $\begin{array}{c}\text { Meta 1: Educação Infantil } \\
\text { Meta 2: Ensino Fundamental } \\
\text { Meta 3: Ensino Médio } \\
\text { Meta 5: Alfabetização na idade certa }\end{array}$ \\
\hline $\begin{array}{c}\text { Grupo } 2 \text { - Inclusão educacional, diversidade e } \\
\text { equidade }\end{array}$ & $\begin{array}{c}\text { Meta 4: Educação Especial } \\
\text { Meta 8: Educação de jovens e adultos } \\
\text { Meta 9: Alfabetização de jovens e adultos }\end{array}$ \\
\hline Grupo 3 - Qualidade da educação básica & $\begin{array}{c}\text { Meta 6: Educação em tempo integral } \\
\text { Meta 7: Melhoria da qualidade da educação } \\
\text { básica }\end{array}$ \\
\hline Grupo 4 - Educação profissional & $\begin{array}{c}\text { Meta 10: Educação de jovens e adultos } \\
\text { integrada à educação profissional } \\
\text { Meta 11: Educação profissional de nível } \\
\text { técnico }\end{array}$ \\
\hline
\end{tabular}




\begin{tabular}{|c|c|}
\hline Grupo 5 - Educação superior & $\begin{array}{c}\text { Meta 12: Acesso à Educação Superior } \\
\text { Meta 13: Melhoria da qualidade da Educação } \\
\text { Superior } \\
\text { Meta 14: Acesso à pós-graduação }\end{array}$ \\
\hline $\begin{array}{c}\text { Grupo } 6 \text { - Formação e valorização dos } \\
\text { profissionais da educação }\end{array}$ & $\begin{array}{c}\text { Meta 15: Formação de profissionais da } \\
\text { educação } \\
\text { Meta 16: Formação continuada de } \\
\text { profissionais da educação } \\
\text { Meta 17: Valorização dos profissionais de } \\
\text { educação } \\
\text { Meta 18: Carreira dos profissionais da } \\
\text { educação }\end{array}$ \\
\hline Grupo 7 - Gestão democrática & $\begin{array}{l}\text { Meta 19: Gestão democrática/Parte normativa } \\
\text { do Plano Estadual de Educação }\end{array}$ \\
\hline $\begin{array}{c}\text { Grupo } 8 \text { - Articulação entre os sistemas de } \\
\text { educação e financiamento }\end{array}$ & Meta 20: Financiamento \\
\hline
\end{tabular}

Fonte: elaborado pelos autores, 2020.

Este mesmo formato foi aplicado em todos os encontros presenciais, sendo sua dinâmica explicada ao público participante pela GPI da Assembleia Legislativa. Em parceria com o corpo técnico da Secretaria de Estado de Educação (SEE), a GPI também foi responsável pela condução e pelo assessoramento das discussões em cada um dos grupos, expondo o conteúdo das metas originais do Plano e registrando todos os destaques e as alterações aprovadas pelos participantes.

Com relação aos trabalhos realizados em cada Encontro Regional, a GPI afirma que a maioria foi conduzida sem grandes problemas. Os embates que surgiam eram de natureza pessoal, entre desafetos políticos paroquiais. No campo das ideias, tudo foi conduzido dentro da normalidade. Não havia, portanto, um embate contra o processo de discussão. A discrepância nesse padrão foi a edição de Belo Horizonte, que serviu como termômetro para se avaliar como seria a Plenária Final.

A etapa de interiorização do Fórum somou 1.781 intervenções no Plano, entre mudanças nos artigos, metas e estratégias originais, supressões totais ou parciais, inclusões de novas estratégias para metas já existentes e mesmo a criação de metas novas, ${ }^{4}$ numa média de 148 intervenções por encontro. Em termos proporcionais, cada encontro regional alterou, em média, 20\% das estratégias originais do Plano, e, através das inclusões, ampliou-o em 10\%. Baseado no número de encaminhamentos de cada encontro, pode-se dizer que seus perfis variaram bastante. Enquanto encontros como o de Varginha foram mais modestos, com 94 intervenções no total, outros, como o de Belo Horizonte, chegaram a 177. Alguns encontros se destacaram no número de alterações nas estratégias originais do Plano (foram 128 em Diamantina), já outros se destacaram pelo número de inclusões (77 em Montes Claros). Entre as alterações no corpo das metas propriamente ditas, o encontro de Paracatu se restringiu a fazer 5, enquanto em Uberlândia foram 16.

\footnotetext{
${ }^{4}$ As alterações foram compostas da seguinte forma: 1.100 mudanças nas estratégias originais, 113 mudanças no texto das metas, 74 supressões, 494 inclusões de novas estratégias dentro das metas originais e 5 novas metas que reuniam 9 estratégias inéditas.
} 
Gráfico 1 - Intervenções nos 12 encontros regionais por tema

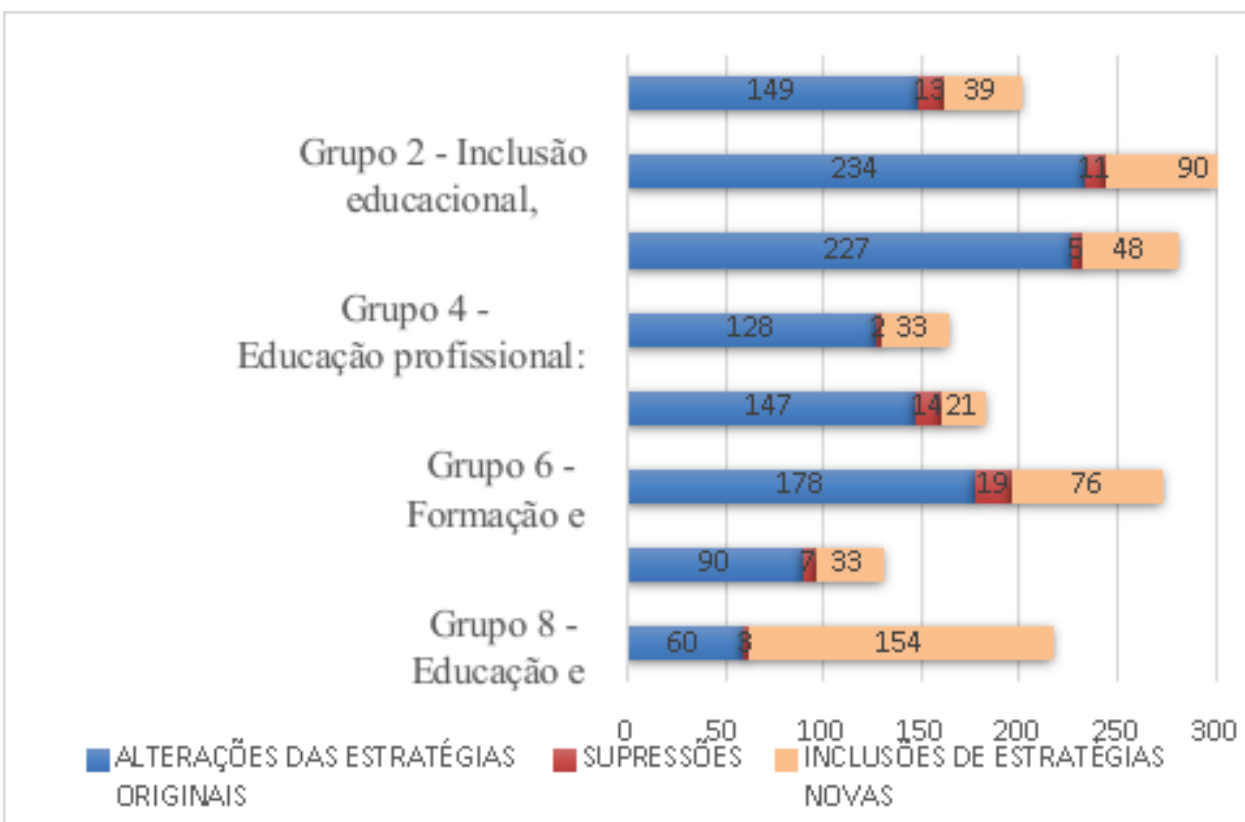

Fonte: elaborado pelos autores, 2020.

Não apenas o número de intervenções variou, mas também em quais metas se concentraram. Em todos os 12 encontros, as metas 13 e 17 sofreram apenas 21 alterações em suas estratégias originais. Por sua vez, a meta 7 acumulou um total de 145 . Proporcionalmente, a meta 20 também se destacou no grande número de alterações, chegando a um valor $750 \%$ maior do que a quantidade de estratégias originalmente previstas. A meta 20 também foi a que acumulou o maior número de inclusões, 154 no total. Dos 12 encontros, 10 realizaram mudanças no texto original das Metas 16 e 17, ao passo que a Meta 2 teve seu texto alterado apenas uma vez.

O contorno da distribuição de alterações, supressões e inclusões entre as 20 metas do Plano é uma das principais evidências de como diferentes forças e grupos de pressão se organizaram para fazer valer seus interesses nesta nova arena de debates. Tanto a amplitude quanto a profundidade desta etapa do Fórum Técnico contribuíram para favorecer determinadas entidades em detrimento de outras, percebendo-se a adoção de diferentes estratégias mesmo para etapas seguintes da tramitação do PEE no âmbito do Legislativo. De acordo com Thomas e Grindle (1990, p. 1173).

Apresentamos dois cenários amplos de reação/resposta à mudança de política. As características da política determinam quais cenários são prováveis de ocorrer. Um conjunto de características tende a gerar uma reação pública às iniciativas reformistas. Neste caso, as apostas para o governo e as elites em exercício são altas e recursos consideráveis são necessários para sustentar a reforma. Um conjunto diferente de características leva a uma resposta na arena burocrática, onde as apostas são mais baixas. Neste segundo cenário, recursos substanciais são necessários para sustentar a reforma, embora eles tendam a ser de natureza diferente dos recursos necessários para sustentar uma reforma que é implementada em grande parte na arena pública. 
As etapas de consulta pública do Fórum Técnico e deliberação parlamentar dentro do processo legislativo se correlacionam com os cenários apresentados pelos autores, envolvendo a deliberação pública e burocrática, de forma a se complementarem no caso do PPE. A relação entre atores públicos e terceiro setor não se mostrou estanque, percebendose variações na aproximação entre determinados órgãos públicos e associações da sociedade civil a depender do que estava sendo pautado. Um exemplo é a atuação do Sindicato Único dos Trabalhadores em Educação (Sind-UTE), muitas vezes em parceria com a SEE e parlamentares de setores considerados mais progressistas do Parlamento para pautas como defesa de direitos trabalhistas e o combate à discriminação. Por outro lado, esse mesmo conjunto de atores, muitas vezes, protagonizava embates entre si, a exemplo das discussões sobre financiamento.

Ao mesmo tempo que as intervenções realizadas nesta etapa regional foram numerosas, era também possível classificá-las em torno de eixos orientados tanto pela natureza de seu conteúdo quanto por sua recorrência em diferentes encontros. ${ }^{5}$ Estabelecimentos de prazos, delimitações de público-alvo, diversificação de profissionais em determinadas estratégias, maior responsabilização do cumprimento das metas, cooperação entre entes federados e categorias profissionais de apoio ao ensino, diferenciações entre redes pública e privada, alterações nos processos decisórios, entre outras, são externalidades das disputas de interesse dos diferentes grupos de pressão que ocorrem como pano de fundo não apenas do Fórum Técnico, mas de toda a tramitação do Plano na ALMG.

Baseado nos documentos finais de cada Encontro Regional, classificaram-se os tipos de intervenção em 5 eixos. O primeiro se refere à Escola Pública versus Privada, uma dualidade histórica na qual se percebe um esforço em beneficiar os profissionais da educação do segmento público ou sanar questões que diziam respeito à sua realidade. O segundo eixo está relacionado à Governança, que envolve todas as intervenções no Plano ligadas à participação popular e de demais profissionais da educação no processo decisório da realidade escolar, incluindo propostas na forma de eleição de conselhos, diretorias e outros cargos de liderança na rede de ensino. O terceiro eixo, Cooperação, diz respeito não apenas entre entes federados, mas também entre outros poderes constituídos e profissionais que auxiliam indiretamente na estrutura de ensino (psicólogos, assistentes sociais). Permanência, Inclusão e Acessibilidade foi o quarto eixo, voltado tanto para a garantia de manutenção da assiduidade dos que já frequentam a escola como para a ampliação do acesso àqueles que, seja por questões sociais, econômicas ou geográficas, são impossibilitados de integrar o sistema de ensino formal. Combate à evasão, chamamentos públicos e políticas afirmativas são os principais orientadores das intervenções aqui dispostas. Por fim, o eixo de Financiamento (que concentrou o maior número de inclusões

${ }^{5}$ Nos encontros regionais, foram recorrentes inclusões de termos como “divulgar”, "expandir”, "garantir”, “estimular”, “implementar”, “assegurar”, "subsidiar” dentro das estratégias originais do Plano. 
de novas estratégias entre todas as 20 metas) contemplou todas as mobilizações em torno de valorização salarial, investimentos em estrutura e tecnologia e apoio a estudantes carentes via incentivos financeiros.

A disposição de atores em torno das discussões do PEE na etapa do Fórum Técnico permite avaliar a dispersão de custos, organização dos grupos de pressão, grau de concentração de benefícios do governo e parlamento e como a profundidade técnica do conteúdo da reforma é capaz de alterá-la. A recepção das alterações feitas na arena pública (Fórum Técnico) pela Assembleia dá o tom de como a arena burocrática delineia o novo contorno do que foi proposto na etapa de tramitação legislativa do plano. Isto posto, o PEE poderia ser considerado uma reforma de abrangência total (todo o estado de MG), de alta exigência técnica e mobilização de recursos burocráticos (THOMAS; GRINDLE, 1990). Os 12 Encontros Regionais contaram com 3.630 inscrições, sendo 2.821 presentes, dispostos entre entidades da sociedade civil organizada, órgãos públicos ou mesmo sem qualquer vinculação - um comparecimento de 77\% em média. Baseado na disponibilidade dos dados sobre as inscrições, foi possível estabelecer 15 diferentes segmentos: Ensinos Infantil, Básico e Superior, Executivo e Legislativo Estaduais e Municipais, Movimentos Estudantil e Social, Grupos Confessionais, Comércio/Indústria/Educação Profissional, Sindicatos, Terceiro Setor, Não informado e Outros. Apesar do delineamento dos participantes dos encontros em grupos e do mapeamento das principais alterações percebidas em cada uma das edições, a GPI chama a atenção para a impossibilidade de se estabelecer uma relação de causa e efeito das intervenções com o perfil da composição dos grupos de debate. Isto porque as votações de cada encontro não tiveram seu registro nominal. Dessa forma, a análise da relação entre proposições aprovadas e participação dos inscritos deve ser feita com cautela.

Apesar da grande variedade de segmentos, há um desnível no número de participantes ligados a cada um. "Ensino Básico" e "Executivo Estadual” concentram o equivalente a todos os representantes dos demais segmentos somados. Isso não significa, no entanto, que há uma relação direta entre o número de intervenções e o número de representantes de determinado segmento. Na verdade, o sucesso de um grupo esteve muito mais relacionado à sua mobilização e organização do que seu número de representantes. Divididos entre os Grupos Temáticos e com capilaridade no Estado, grupos como SindUTE (pertencente a um segmento relativamente pouco expressivo, dos Sindicatos) foram capazes de realizar intervenções de peso.

Os dados reunidos e aqui expostos em forma de gráficos apontam uma clara presença das escolas estaduais não apenas em todos os encontros regionais, mas também em todos os grupos temáticos, notadamente os de Inclusão Educacional e Diversidade, Qualidade da Educação Básica Formação e Valorização dos Profissionais e Gestão Democrática. De acordo com a GPI, era visível a atuação de segmentos específicos, mais engajados e mobilizados em torno de determinadas questões. Para muitos grupos temáticos, 
já possuíam mesmo uma avaliação prévia e um conjunto de sugestões. Dentre as muitas entidades inscritas, o Sind-UTE, a União Nacional dos Dirigentes Municipais de Educação (Undime) e a União Nacional dos Conselhos Municipais de Educação (UNCME) se destacam, representando, ao longo desta etapa, o debate que não foi feito para a construção da minuta do Plano enviada pela SEE, espelhada no PNE.

Na Etapa Final do Fórum Técnico, realizaram-se análises, consolidação e aprovação das propostas priorizadas nos Encontros Regionais e da Consulta Pública, sendo definida de forma terminativa a redação das propostas originais do Plano. Realizada entre os dias 15 e 17 de junho de 2016 nas dependências da ALMG, seguiu essencialmente os mesmos moldes dos encontros regionais, com grupos de trabalho divididos nos oito grupos temáticos. Naturalmente, a dimensão das discussões também haviam se alterado, envolvendo agora todas as propostas aprovadas nos encontros regionais, além das eventuais propostas e destaques que surgissem na ocasião. A composição dos participantes, sua distribuição entre os grupos temáticos e as novas regras estabelecidas para a Etapa Final são novidades que tornam este momento do Fórum Técnico uma arena totalmente nova, em que novas estratégias e mobilizações foram postas em prática para que se fizesse valer determinadas agendas e pautas em detrimento de outras. Por estar concentrada na capital e por representar a conclusão de um esforço que percorreu todo o Estado, foi também a oportunidade de reunir com mais força todos os atores envolvidos nas discussões do Plano, seja por parte do Poder Público, da sociedade civil organizada ou da iniciativa privada.

De acordo com a GPI, mesmo os pontos mais controversos, que fomentaram os principais antagonismos e impasses ao longo das discussões, foram conduzidos da melhor maneira possível. Especificamente com relação à questão de gênero, presenciou-se uma polarização na qual todos que quiseram se posicionar tiveram espaço para tal. A parcela minoritária da plenária final, contrária à pauta de gênero, valeu-se de todos os recursos legítimos de obstrução que o regulamento eventualmente permitia, e foram fazendo isso até que as questões foram sendo superadas por um processo de agregação de preferências (exercício da regra de maioria).

Todo o trabalho realizado ao longo dos três dias de discussão resultou num Documento Final de Propostas com todas as intervenções aprovadas. A análise sobre seu conteúdo permite concluir que o Plano cresceu em detalhamento e profundidade entre as metas originais e em volume pela quantidade de estratégias novas. A maior robustez das metas e estratégias originais se deu em função de estabelecimentos de prazos e percentuais mais claros, delimitações ou ampliações de público-alvo, diversificação de profissionais no atendimento ao sistema de ensino (em espacial nas áreas de Saúde e Assistência Social), clareza quanto a responsabilização do cumprimento das metas pelo Plano, cooperação entre os entes federados, parcerias entre entidades públicas, privadas e da sociedade civil organizada, valorização do papel dos profissionais de educação nos processos decisórios, ênfase na participação e fiscalização popular e ampliação das tarefas dentro de cada 
estratégia, adequação das estratégias e metas às peculiaridades locais e regionais e criação de ações afirmativas.

O Fórum Técnico representou a primeira oportunidade de efetivamente se propor mudanças quanto ao conteúdo do PEE. Como se pôde observar, o formato amplamente participativo e descentralizado favoreceu as entidades com maior capilaridade no estado e com propostas de intervenção mais bem definidas. Nesse aspecto, cabe destaque aos segmentos da educação básica e sindicatos, seguidos em menor grau pelo movimento estudantil e LGBT. O volume de proposições voltadas para esses segmentos inseridas ao longo dos Encontros Regionais e aprovadas na Etapa Final demonstra a capacidade de mobilização desses movimentos. Na Etapa Final, entidades de perfis variados se organizaram em torno de bandeiras comuns, geralmente voltadas a políticas afirmativas e de proteção a minorias. Essa mobilização foi determinante para o sucesso dessa agenda, tendo em vista a maior dificuldade para formação de maiorias que aprovassem as propostas, dado o grande número de participantes. Baseado no tipo de propostas aprovadas no Fórum Técnico, as grandes contribuições dessa etapa para o Plano foram: ampliação da participação dos profissionais da educação no processo decisório das questões escolares, valorização dos planos de carreira, melhores condições de trabalho para o corpo docente e ampliação de políticas voltadas para a proteção de minorias sociais. $\mathrm{O}$ fato de o projeto original do PEE ter se restringido ao alcance de metas gerais de melhoria de indicadores na educação em determinados prazos (a exemplo do que está contido no PNE) deixou um amplo espaço para intervenção e detalhamento das metas e estratégias do Plano.

\section{A Tramitação Legislativa do Plano Estadual de Educação}

A arena da tramitação legislativa do Plano representou uma reconfiguração de forças no que diz respeito às disputas de interesses entre atores e grupos envolvidos na sua construção. Se na arena do Fórum Técnico os atores mais beneficiados foram os que mais tinham capilaridade no estado, mais marcaram presença nos encontros regionais e mobilizaram o maior número de pessoas na Etapa Final, as estratégias mais bem-sucedidas no momento de tramitação legislativa estiveram muito mais relacionadas à articulação das entidades perante os parlamentares, por meio de organização e convencimento.

Os calorosos debates motivados pelos mais diversos setores da sociedade civil que se envolveram no Fórum Técnico do PEE, nos meses de fevereiro e junho de 2016, deram lugar a uma prolongada e relativamente discreta tramitação no âmbito do processo legislativo na ALMG. Como prevê o Regimento Interno da Assembleia de Minas, o PEE, pela natureza de seu conteúdo e implicação de suas proposições, necessitava tramitar por quatro Comissões Temáticas permanentes: a Comissão de Educação, Ciência e Tecnologia, Constituição e Justiça, Fiscalização Financeira e Orçamentária e Administração Pública. Tendo em vista a necessidade de composição de quórum para 
abrir as reuniões ordinárias das comissões, com a possibilidade de se pedir vista por parlamentar membro de comissão, bem como retirada da discussão de proposição da ordem do dia em Comissão ou Plenário, o Plano passava a estar sujeito a uma série de variáveis que acabariam por interferir no ritmo de sua tramitação. Uma das principais consequências desse cenário era a possibilidade de o Plano estar suscetível a reorganizações políticas capazes de interferir em seu conteúdo.

O ano de 2017 representou uma mudança no cenário político em torno do PEE que influenciou fortemente sua tramitação. Primeiramente, Paulo Lamac, principal articulador do Fórum entre os parlamentares, foi eleito vice-prefeito de Belo Horizonte nas eleições municipais de 2016, afastando-se dos trabalhos da ALMG. Ao mesmo tempo, a entrada do ano de 2017 representava a entrada do $2^{\circ}$ Biênio da Legislatura, momento em que a composição das Comissões e Mesa Diretora da ALMG era reformulada. Isso significou um impacto significativo no perfil ideológico da Comissão de Educação, principalmente em função da substituição da presidência de Paulo Lamac por Celise Laviola (MDB). A saída de Ione Pinheiro (DEM) do cargo de suplência para a vice-presidência reforçou o novo perfil que se formava nessa segunda metade da Legislatura na Comissão de Educação. Mais do que a troca de postos entre parlamentares, a nova configuração das Comissões reorganizava a arena de disputa dos atores sociais que estiveram presentes nos trabalhos do Fórum. Sem uma plataforma voltada exclusivamente para o Plano, as discussões em torno de seu conteúdo passaram a ser em gabinetes, reuniões ordinárias e audiências públicas de iniciativa das Comissões.

Para amplificar vozes que não se mostraram majoritárias na Etapa Final do Fórum Técnico, foi convocada pela Comissão de Educação uma audiência pública no dia 19 de setembro de 2017. Apesar de voltada essencialmente para discutir a Base Nacional Curricular Comum (BNCC), a audiência pública convocada pela Comissão de Educação no dia representou uma nova arena de debate para que atores e grupos, até então minoritários nas discussões do Plano, tivessem a oportunidade de demonstrar seu peso e representatividade como sociedade civil organizada.

De acordo com a Gerência de Projetos Institucionais, a estratégia, adotada pela deputada, de se criar novas plataformas de debate para temas de grande repercussão não é incomum. Em grandes eventos, as Comissões de mérito costumam ser influenciadas pelas pautas mais abrangentes dos eventos institucionais, seja para tornar mais complexa a discussão, seja para dar voz a grupos que se sentiram marginalizados. O viés conservador da audiência contribuiu para reforçar o argumento da necessidade de se evitar a abordagem das questões de gênero e sexualidade tanto da BNCC quanto do PEE.

A estratégia de criação dessa nova plataforma de debates não apenas viabilizou o uso de uma nova arena com atores específicos, mas também fundamentação e legitimidade para que consideráveis mudanças no conteúdo do Plano fossem feitas naquele momento. A percepção de muitos atores sociais e políticos até então secundários no processo de 
discussão demonstrou a complexidade das disputas em torno do PEE e as diferentes estratégias empregadas por grupos de composição numericamente distinta. Segundo Sebastian (1999, p. 3, tradução nossa):

Parece provado que grupos pequenos, homogêneos, bem comunicados e organizados, com grandes incentivos e objetivos precisos, têm maior probabilidade de alcançar seus objetivos do que grupos grandes, informais ou mal articulados, cuja ação não tem objetivos precisos ou os incentivos para isso não são significativos em comparação com o esforço requerido.

Após aprovação do parecer em $1^{\circ}$ Turno pela Comissão de Educação, o substitutivo n 1 da relatoria da Deputada Celise passa pela Comissão de Administração Pública para apreciação, em 26 de setembro de 2017. O Plano é então aprovado na forma do substitutivo $\mathrm{n}^{0}$ 2, apresentado pelo deputado Durval Ângelo, relator da Comissão, na reunião do dia 13 de novembro de 2017. Os levantamentos feitos pela relatoria se relacionam principalmente com os princípios da separação de poderes e a vedação de criação de novas despesas, cargos, funções ou empregos públicos na administração direta e indireta ou aumento de sua remuneração por iniciativa do Legislativo em projetos de competência exclusiva do Executivo. Dessa forma o substitutivo ${ }^{0} 2$ propôs um Plano com 15 artigos na parte normativa, 18 metas e estratégias.

Passada a fase de tramitação em Comissões, o Plano vai a Plenário para votação em $1^{0}$ Turno em dezembro de 2017. Na ocasião, 16 emendas ao projeto foram propostas, exigindo que ele retornasse à Comissão de Educação para emitir parecer. Apesar do volumoso número de intervenções feitas em plenário, a Comissão de Educação, Ciência e Tecnologia trouxe seu parecer 2 dias depois da reunião em Plenário, pela rejeição de todas as emendas, tendo apresentado uma $18^{\mathrm{a}}$, que propõe incluir o Tribunal de Contas entre as instâncias de monitoramento do Plano. De acordo com a relatora, Celise Laviola, as emendas foram rejeitadas por sua redundância com outros dispositivos que já constavam no Plano. Apesar do impasse das emendas ter se resolvido em tempo hábil, o Plano acaba saindo da pauta de votação, voltando somente um ano depois, em 13 de novembro de 2018. A partir daí, é aprovado com celeridade, sem novas alterações, sendo votado em $2^{\circ}$ turno na Comissão de Educação em 14 de novembro e retornando para votação em $2^{\circ}$ Turno no Plenário no dia 20 do mesmo mês. No dia 5 de dezembro, vai à Comissão de Redação com parecer pela aprovação pelo Deputado Tadeu Martins Leite.

\section{Conclusão}

A análise da tramitação do PEE, nas diferentes arenas de discussão e decisão oferecidas pela ALMG, permite que se façam alguns apontamentos não apenas quanto ao papel do Legislativo na formulação do Plano, mas também na maneira como os atores envolvidos se organizaram no atendimento de seus interesses. Em primeiro lugar, a ALMG foi bem-sucedida em criar plataformas para que diferentes grupos envolvidos nas discussões do Plano pudessem expor seus posicionamentos e sugestões de intervenção 
nas estratégias e metas. Baseado nos recursos disponíveis para vocalizar seus interesses, as entidades envolvidas (Fórum Técnico, audiências públicas, consultas on-line) buscaram se concentrar nos ambientes de debate que julgavam possuir mais força ou influência. Em segundo lugar, a própria natureza política do Legislativo contribuiu para que mudanças na condução do Plano fossem tomadas, demonstrando uma janela de oportunidade para determinados grupos cujas opiniões não prevaleceram em arenas de discussão anteriores.

Na etapa de regionalização do Fórum Técnico, o grau de capilaridade da arena em Minas afora dava às entidades de maior inserção no estado a possibilidade de fazerem prevalecer seus interesses. A organização em torno de intervenções constantes sobre os mesmos pontos também representou uma importante estratégia nessa etapa. Baseado em tais recursos, destacam-se o Sind-UTE e os professores da rede básica de ensino como entidades que influenciaram intensamente as proposições do Plano (a primeira pela repetição de intervenções na maior parte dos encontros regionais, a segunda pelo grande número de participantes presentes). O grande volume de intervenções nas áreas de valorização dos profissionais de educação e financiamento são evidências do esforço concentrado destes dois segmentos e outros correlatos. Obviamente, isso não impediu que outros segmentos menos abrangentes no estado não fossem capazes de inserir suas propostas. Afinal, bastava a participação em um único encontro regional para garantir as intervenções. Nesse sentido, destacaram-se associações ligadas ao movimento estudantil e à militância LGBT, cuja presença foi mais marcante nas últimas edições da etapa, notadamente na de Belo Horizonte.

Por fim, o formato da arena da tramitação legislativa (capitaneada pelos próprios parlamentares) deu a oportunidade de que agendas de entidades até então preteridas nas etapas anteriores pudessem prevalecer. Para tanto, o mapeamento das inclinações ideológicas de cada parlamentar, para se pensar em abordagens distintas de convencimento, mostrou-se o principal recurso desta derradeira arena de discussão. A identificação dos atores políticos mais relevantes para influenciar no conteúdo do Plano (notadamente a relatoria da comissão de educação, que exerceu um papel fundamental nesta etapa) também contribuiu para que a afinidade ideológica entre entidades e parlamentares conservadores garantisse um novo formato para o PEE.

Há também temas relevantes para reflexão futura. Questões caras às abordagens institucionalistas, como a maneira pela qual o desenho institucional das arenas decisórias podem redistribuir diferentemente poder entre distintos atores e relevância variada aos diversos recursos políticos, bem como temas relativos a grau, limites e condições em que o Estado pode demonstrar alguma autonomia em relação ao poder desigual das classes sociais e suas frações apontam para possíveis desdobramentos da reflexão proposta.

Diante de toda a complexidade imanente ao PEE e sua tramitação no parlamento mineiro, percebe-se que a representação não se resume à autorização que a população dá 
nos períodos eleitorais, pois a pauta societária tem muitos representantes externos aos poderes constituídos. É desejável que em momentos participativos diversos exista o diálogo com essa representação construída, que na verdade é quem detém o monopólio decisório sobre a condição da política pública. Há um aspecto circular entre representação e sociedade civil, e nessa circularidade a autorização eleitoral, embora seja um elemento potente de legitimação, vai ficando cada vez mais distante do que o representante vai ter que se haver ao longo de seu mandato. O que toma corpo ao longo do mandato é a responsabilidade de responsividade por parte do representante, algo de vital importância, sem sombra de dúvida. O segundo elemento é a capacidade de escuta do representante.

A democracia no padrão ocidental de ascendência liberal se estruturou muito sobre a oralidade e o poder de falar. Talvez esse processo tenha levado os parlamentos a perder seu potencial de escuta. Os processos participativos dialogam com essa vitalidade, algo que pode ser levado ao parlamento como instância de escuta. A representação é um processo de escuta, porque o parlamentar, ao longo de seu mandato, vai ser desafiado várias vezes, questionado se ele é ou não o representante daquela temática, pois isso será disputado por outros representantes da sociedade civil. O parlamentar renova ao longo do mandato as suas pretensões de representação, às vezes mudando as suas pautas em virtude desse debate. Dessa forma, o parlamento, com processos regulares de participação, pode contribuir muito com essa estratégia do mandato parlamentar, o que é, também, uma estratégia de escuta.

\section{Referências}

ANASTASIA, Fátima; SANTOS, Manoel Leonardo dos (Org.). Política e desenvolvimento institucional no legislativo de minas gerais. Belo Horizonte: Editora PUC Minas, 2016. 516 p.

COUTO, Cláudio Gonçalves. Sistema de Governo e políticas públicas. Brasília: Enap, 2019. $136 \mathrm{p}$.

CUNHA, Eleonora Schettini M.; MENDONÇA, Ricardo Fabrino. Participação ampla sem deliberação? In: SANTOS, Manoel Leonardo; ANASTASIA, Fátima (Org.). Política e desenvolvimento institucional no legislativo de Minas Gerais. Belo Horizonte: Editora PUC Minas, 2016. 516 p.

MANDELKERN. Group On Better Regulation. Final report. [s/l]. 2001. Disponível em: http://ec.europa.eu/smart-regulation/better_regulation/documents/mandelkern_report.pdf. Acesso em: 17 set. 2018.

MOLINA, Carlos Gerardo. Las reformas educativas en américa latina: hacia una mayor equidad? Washington DC: Banco Interamericano de Desarrollo, 2002.

SAIEGH, Sebastian M. Active players or rubber stamps? An evaluation of the policymaking role of Latin American legislatures. In: SARASIN, Carlos; STEIN, Ernesto; TOMMASO, Mariano Tommaso (Org.). How democracy works: political institutions, actors, and arenas in Latin American policymaking. Cambridge: Inter-American Development Bank, 2010. 336 p.

SEBASTIAN, Luis de. “Análisis de los involucrados”. Serie de Documentos de Trabajo I14 UE. Washington DC: Banco Interamericano de Desarrollo, 1999. 75 p. 
THOMAS, John W.; GRINDLE, Merilee S. After the decision - implementing policy reforms in developing countries. Word Development, v. 18, n. 8, Printed in Great Britain, 1990, pp. 1163-1181.

Recebido em: 05/03/2020

Aprovado em: 01/06/2020 